East African Medical Journal Vol. 86 No. 9 September 2009

FACTORS ASSOCIATED WITH DELAYED DIAGNOSIS OF HIV INFECTION IN MUKONO DISTRICT, UGANDA

J. B. M. Ddamulira, MBChB, DHSM, MPH, Assistant Lecturer, Department of Disease Control and Environmental Health E. Rutebemberwa, MBChB, MPH, Research Fellow, Department of Health Planning Policy and Management, Makerere University, Institute of Public Health, P.O. Box 7072, Kampala, Uganda, E. Tumushabe, MBChB, MPH, Director, District Health Services, Mukono, District Local Government, P.O. Box 53, Mukono, Uganda and F. Nuwaha, MD, PhD, Senior Lecturer, Department of Disease Control and Environmental Health, Makerere University, Institute of Public Health, P.O. Box 7072, Kampala, Uganda

Request for reprints to: Dr. J. B. M. Ddamulira, Makerere University Institute of Public Health P.O. Box 7072, Kampala, Uganda

\title{
FACTORS ASSOCIATED WITH DELAYED DIAGNOSIS OF HIV INFECTION IN MUKONO DISTRICT, UGANDA
}

\author{
J. B. M. DDAMULIRA, E. RUTEBEMBERWA, E. TUMUSHABE and F. NUWAHA
}

\begin{abstract}
Objective: To identify factors associated with delayed diagnosis of HIV infection.

Design: Cross sectional study.

Setting: Mukono district, Uganda.

Subjects: Newly diagnosed HIV positive clients at ten HIV testing centres. Late testers were HIV positive clients who had AIDS according to World Health Organisation AIDS case definition. Early-testers did not have AIDS at diagnosis.

Main outcome measures: Late testers were compared to early testers on socio-demographic characteristics, sexual behaviour, access of testing services, knowledge of care and support services for HIV/AIDS and attitude towards knowing HIV-status.

Results: Delayed diagnosis of HIV infection was independently associated with being over 25 years (adjusted odds ratio (AOR), 4.3; Confidence Interval (CI) 1.7-11.1), not being married (AOR, 2.4; CI 1.3-4.4), having no knowledge of testing services (AOR, 2.4; CI, 1.2 4.7), spending at least one hour travelling to a testing centre (AOR, 2.1; CI, 1.0-4.2), paying for HIV testing (AOR, 3.4; CI, 1.7-6.9) having had an illness two months before testing AOR 9.49; $\mathrm{CI}, 4.84-18.64)$ and having negative beliefs towards knowing one's HIV sero status (AOR, 5.7; CI, 1.0-30.8).

Conclusion: Factors associated with delayed diagnosis of HIV infection in Mukono District of Uganda are; age over 25 years, not being married, having no knowledge of testing services, paying for HIV testing, travelling for at least one hour to a testing centre and having negative beliefs towards knowing one's HIV status. In order to increase access to testing there is need to offer free HIV testing and health education targeting people above 25 years and those not married.
\end{abstract}

\section{INTRODUCTION}

Late diagnosis (just after development of AIDS and or after fall of CD4+ below 200) of the Human Immunodeficiency Virus (HIV) that causes Acquired Immunodeficiency Syndrome(AIDS) is widespread in high as well as low income countries $(1,2)$. A desired goal for HIV prevention and care in the era of highly active anti-retroviral therapy (HAART) is to diagnose all infections early so as to plan for prevention, and care or for initiation of HAART (3). The consequences of late diagnosis include non-reduction in HIVtransmission risk behaviours and poor response to therapy with HAART leading to increased incidence of HIV associated mortality and morbidity $(4,5)$.
InUganda, less than $10 \%$ of the adult population has ever undertaken an HIV test inspite of the mature HIV epidemic with about $7 \%$ of the population infected (6). Moreover of the few that have ever undertaken an HIV, more than $60 \%$ test for AIDS related symptoms (7). This means that mortality and morbidity of people who initiate treatment remains high as stage of immuno-suppression highly predicts outcome of treatment (8). Whereas factors influencing timing of HIV diagnosis have been studied in high income countries such data is hardly available in low income countries $(9,10)$. Yet they are low income countries that have the highest burden of HIV infection as well as highest prevalence of late diagnosis. This work was aimed at understanding 
the factors influencing the timing of HIV diagnosis in a low income setting of Uganda with a view of suggesting measures for reducing late diagnosis of HIV.

\section{MATERIALS AND METHODS}

We compared early and lateHIV testers from tenhealth facilities in Mukono District of Uganda. Mukono district has an estimated population of 800,000 people on the basis of 2002 national census and over $70 \%$ of the population being rural dwellers. It is estimated that $9.5 \%$ of the adult population in the district are infected with HIV. In Mukono district, HIV diagnosis is mainly through voluntary counselling and testing (VCT) services. These services were initiated in 2001 at three health facilities that have to date been expanded to 17 health facilities. Prevention of mother to child transmission of HIV (PMTCT) services started in 2003 has been integrated into antenatal and maternity services. Besides HIV counselling and testing, all the 17 facilities offering HIV testing provide treatment for opportunistic infections. Treatment of HIV / AIDS with ARVs is provided at only three of the 17 health facilities that offer VCT.

Sample size: We aimed at interviewing 290 respondents (145 late testers and 145 early testers). This sample size is large enough to achieve $5 \%$ level of significance ( $95 \%$ confidence interval) and a study power of $80 \%$ with a detectable relative risk of 2 provided that the determinants of timing of HIV testing within the study population are not common (less than 15\%) or very common (greater than $85 \%$ ).

Selection of study participants: Ten health facilities (out of the 17 health facilities) that provide HIV testing in the district and had the highest number of client load were selected. Clients aged 18 years and above who voluntarily requested and tested HIV positive for the first time during the study period (February $21^{\text {st }}$ to April $30^{\text {th }} 2005$ ) were eligible for inclusion. All clients who tested HIV positive were interviewed, had medical history taken and were examined for signs and symptoms suggestive of AIDS.

Data collection instruments: These included a precoded, pre-tested questionnaire and a checklist for signs and symptoms of AIDS. The instruments were administered by research assistants trained on WHO classification (clinical officers and medical doctors) whose routine work involved treatment and care of HIV positive patients.

Dependent variable: Timing of HIV diagnosis (latetester or early tester) was the outcome measure of interest. A late tester was any HIV positive patient who had two or more major and two or more minor signs and symptoms according to WHOcase definition of AIDS disease on testing HIV positive for the first time. An early tester was an HIV positive patient who had less than two major and less than two minor signs and symptoms according to WHO case definition of AIDS disease (11). A diagnosis of AIDS was made using the WHO case definition of AIDS basing on the signs and symptoms a client presented with on the same day of testing HIV positive since the CD4 counts were not available.

Independentvariables: Theindependent variables were age, sex, ethnic background, religion, marital status, education, distance to testing centre, time taken to reach a testing centre, paying for HIV testing, knowledge of availability of HIV testing services, risk behaviours; and attitude towards knowing one's HIV sero status.

Dataanalysis:SPSSstatistical software package version 12.0 (SPSS Inc., Chicago, IL) was used in the analysis. Univariate analysis was done to generate frequencies and proportions and comparisons were made between late and early testers using crude odds ratio (COR) and their $95 \%$ confidence intervals (CI). To determine independent predictors of timing of HIV diagnosis, stepwise multivariate logistic regression procedures were used. All variables which were significant at bivariate analysis were included in the multivariate analysis. Adjusted odds ratios (AOR) were calculated after multivariate analysis.

Ethical consideration: The research was approved by the research and ethics committee of Makerere University Institute of Public Health. Permission to collect data was sought from district authorities and in-charges of the health facilities, and informed consent was obtained from subjects before interview. Anonymous identifiers were used for confidentiality.

\section{RESULTS}

During the months of February, March and April 2005, a total of 3849 clients tested for HIV infection at ten primary health care facilities. Four hundred and eight clients tested positive giving a prevalence rate of $10.6 \%$ among testers. Of the $408 \mathrm{HIV}$ positive clients, $263(65 \%)$ were late testers and $145(35 \%)$ were early testers. Since the study design aimed at enrolling an equal number of late and early testers the first 145 late testers were included whereas all the early testers were included.

Factors influencing timing of testing: The factors influencing timing of HIV testing are considered under socio-demographic variables, accessibility of testing centres, behaviour characteristics and under attitude towards knowing one's HIV sero 
status. In addition, both the results of univariate and multivariate analyses are presented.

Socio-demographic characteristics and accessibility of testing services: Comparison of early testers and late testers regarding the socio-demographic characteristics and accessibility to testing centres at univariate analysis (Table 1). Delayed diagnosis of HIV was more likely in people that are over 25 years, are not married, travel more than five kilometres to reach an HIV testing centre, spend more than one hour of travel to reach to a testing centre, had no knowledge of availability of testing services and people that paid money for HIV testing. Sex and education of the respondent did not influence time of testing for HIV.
Behavioral characteristics and attitudinal beliefs affecting HIV diagnosis: The behavioural factors and attitudinal beliefs that favoured delayed diagnosis of HIV are: consuming alcohol, having an illness in the previous two months, knowing pregnant women as people who should be testing and having negative belief towards knowing one's HIV sero status (Table 2). Number of sexual partners, having casual sex in previous year, using condom during casual sex, place visited for medical consultation, kind of people to test and reasons for knowing sero status were not significantly associated with timing of HIV diagnosis (Table 2). Late testers had a high likelihood of mentioning quick progress of the disease and dying faster as a negative effect to knowing sero status than early testers (COR, 2.0; $95 \%$ CI, 1.9-3.7).

Table 1

Socio-demographic and accessibility factors associated with delayed diagnosis of HIV infection in Mukono District,

\begin{tabular}{|c|c|c|c|}
\hline \multirow[t]{2}{*}{ Variable } & \multirow{2}{*}{$\begin{array}{l}\text { Late testers } \\
(\mathrm{n}=145) \\
\text { No }(\%)\end{array}$} & \multirow{2}{*}{$\begin{array}{l}\text { Early testers } \\
(\mathrm{n}=145) \\
\text { No. }(\%)\end{array}$} & \multirow[t]{2}{*}{$\begin{array}{l}\text { Crude Odds Ratio } \\
(95 \% \text { CI })\end{array}$} \\
\hline & & & \\
\hline Sex (male) & $\begin{array}{ll}52 & 35.9\end{array}$ & $\begin{array}{ll}40 \quad 27.6 \\
\end{array}$ & $1.5(0.9-2.4)$ \\
\hline Age $(\geq 25$ years $)$ & 13391.7 & 1196.6 & $3.4(1.7-6.9)^{\star}$ \\
\hline Education level (pre-secondary) & 10975.2 & 9968.3 & $1.4(0.8-2.4)$ \\
\hline Marital status (not married) & $74 \quad 51.0$ & $47 \quad 32.4$ & $2.2(1.4-3.5)^{*}$ \\
\hline No knowledge of testing services & $53 \quad 36.6$ & $28 \quad 19.3$ & $2.4(1.4-4.1)^{\star}$ \\
\hline Distance to testing centre $(\geq 5 \mathrm{~km})$ & $98 \quad 67.6$ & $69 \quad 47.5$ & $2.3(1.4-3.7)^{*}$ \\
\hline Duration of journey to testing cent & & & \\
\hline (>60 minutes) & $43 \quad 29.7$ & $25 \quad 17.2$ & $2.0(1.2-3.5)^{*}$ \\
\hline Paid for HIV testing (Yes) & 36.6 & 17.9 & $2.6(1.5-4.5)^{*}$ \\
\hline
\end{tabular}

* Statistically significant difference between late and early testers

" Not married includes; divorced/separated, widowed, never in union

Numbers in parentheses are percentages

Table 2

Distribution of behavioural and attitudinal variables among late and early testers in Mukono District, Uganda

\begin{tabular}{|c|c|c|c|c|c|}
\hline Variable & \multicolumn{2}{|c|}{$\begin{array}{l}\text { Late testers } \\
(\mathrm{n}=145) \\
\text { No. }(\%)\end{array}$} & \multicolumn{2}{|c|}{$\begin{array}{l}\text { Early testers } \\
(\mathrm{n}=145) \\
\text { No. }(\%)\end{array}$} & $\begin{array}{l}\text { Crude Odds Ratio } \\
(95 \% \text { CI })\end{array}$ \\
\hline Number of sexual partners $(\leq 1)$ & 112 & 77.2 & 116 & 80.0 & $0.85(0.48-1.49)$ \\
\hline Had casual sex in the last one year (yes) & 56 & 38.6 & 43 & 29.7 & $0.67(0.41-1.09)$ \\
\hline Used condom during casual sex (Yes) & 8 & 14.3 & 7 & 16.3 & $0.86(0.25-2.94)$ \\
\hline Alcohol consumption $(Y e s)^{\wedge}$ & 71 & 49.0 & 52 & 35.9 & $1.72(1.07-2.75)^{*}$ \\
\hline Had illness in the last two months (Yes) & 81 & 55.9 & 17 & 11.7 & $9.53(5.23-17.41)^{*}$ \\
\hline \multicolumn{6}{|l|}{ Place went to for advice $* *$} \\
\hline Public health facility & 41 & 53.9 & 9 & 52.9 & $1.04(0.32-3.36)$ \\
\hline \multicolumn{6}{|l|}{ Who should test for HIV } \\
\hline Everybody (Yes) & 85 & 58.6 & 89 & 61.4 & $0.89(0.56-1.43)$ \\
\hline Chronically ill (Yes) & 23 & 15.9 & 16 & 11.0 & $1.52(0.77-3.01)$ \\
\hline Pregnant women (Yes) & 4 & 2.8 & 18 & 12.4 & $0.20(0.66-0.67)^{*}$ \\
\hline Married people (Yes) & 18 & 12.4 & 28 & 19.3 & $0.59(0.31-1.13)$ \\
\hline
\end{tabular}




\begin{tabular}{|c|c|c|c|c|c|}
\hline $\begin{array}{l}\text { Should know one's HIV sero status } \\
\text { (Agrees) }\end{array}$ & 143 & 98.6 & 133 & 91.7 & $6.45(1.42-29.4)^{*}$ \\
\hline \multicolumn{6}{|l|}{ Why should they know sero-status } \\
\hline Early treatment and care (Yes) & 95 & 65.5 & 100 & 69.0 & $0.86(0.52-1.39)$ \\
\hline To plan for feature (Yes) & 40 & 27.6 & 35 & 24.1 & $1.19(0.71-2.03)$ \\
\hline A void spread of infection (Yes) & 39 & 26.9 & 48 & 33.1 & $0.74(0.45-1.23)$ \\
\hline \multicolumn{6}{|c|}{$\begin{array}{l}\text { *Statistically significant findings } \\
\wedge \text { Only respondents who had had casual sex }(n=99) \\
{ }^{* *} \text { Only those respondents who sought for advice when ill }(\mathrm{n}=93) \\
\text { Numbers in parentheses are percentages }\end{array}$} \\
\hline \multicolumn{6}{|c|}{$\begin{array}{c}\text { Table } 3 \\
\text { Independent predictors of delayed diagnosis for HIV in Mukono District, Uganda }\end{array}$} \\
\hline Variable & & \multicolumn{3}{|c|}{$\begin{array}{l}\text { Adjusted } \\
\text { Odds Ratio }\end{array}$} & $95 \% \mathrm{CI}$ \\
\hline Age (> 25 years) & & \multicolumn{3}{|c|}{4.31} & $1.68-11.09$ \\
\hline Not married & & \multicolumn{3}{|c|}{2.42} & $1.32-4.43$ \\
\hline $\begin{array}{l}\text { Having no knowledge of availability } \\
\text { services }\end{array}$ & & \multicolumn{3}{|c|}{2.39} & $1.21-4.72$ \\
\hline Duration of journey to testing centre & utes) & \multicolumn{3}{|c|}{2.08} & $1.04-4.15$ \\
\hline Having paid for testing & & \multicolumn{3}{|c|}{3.42} & $1.69-6.93$ \\
\hline Had illness in last two months befor & & \multicolumn{3}{|c|}{9.49} & $4.84-18.64$ \\
\hline $\begin{array}{l}\text { Agreeing that one should know one' } \\
\text { status }\end{array}$ & & \multicolumn{3}{|c|}{5.66} & $1.04-30.78$ \\
\hline
\end{tabular}

Multivariate analysis: At multivariate analysis (Table 3) we found that not being married, being older than 25 years, taking at least one hour to reach a testing centre, not having knowledge of testing services, paying money for HIV testing, having had an illness two months before testing and having negative belief towards knowing one's HIV sero status were independently associated with delayed diagnosis.

\section{DISCUSSION}

The variables influencing timing of testing for HIV can be classified into three groups. First are the social-demographics (e.g. age and marital status) representing those sections of the population at risk of delayed diagnosis. Second are barriers and supports (e.g. time taken to reach a testing centre, payment of services, having an illness and knowledge of testing centres) that either make testing decision easy or difficult and third is the belief towards knowing one's sero status and its consequences.

Age was independently associated with timing of HIV diagnosis, with HIV diagnosis more likely to be delayed among older people. This is similar to what has been reported in Europe, $(2,10,12)$ but different from a study in the United States, (13) where young people aged 18-29 years had a high likelihood of testing late than older people. This difference may be explained by the variation in age groups targeted by HIV prevention campaigns in US and Uganda considering a varying distribution of HIV prevalence among the different age groups in the two countries. Many HIV prevention campaigns in Uganda target young people. This may have led to increased awareness on HIV among young people resulting into early HIV diagnosis. This can be further supported by results from other studies in Uganda (e.g.for malaria) where younger people were reported to be early innovators of new programmes and technologies (14). On the other hand since infected people may live for many years before developing AIDS defining signs and symptoms, the association could reflect a recent infection with HIV in young clients than the older clients.

We found marital status strongly associated with timing ofHIV diagnosis with late diagnosis morelikely among unmarried people. Other studies in Uganda demonstrated similar association with married people having a high likelihood of undertaking VCT $(6,14)$. It is worthy noting that prevention of mother to child transmission of HIV infection programmes is widely implemented in Uganda. Since the programmes 
promotes couple testing and it is widely publicised, married people were possibly testing early due to encouragement from their partners. However it is also possible that widowed and divorced people who constituted the biggest proportion of the unmarried may have delayed to test because they thought it not necessary since their partners were either known HIV or were suspected to have died of HIV / AIDS which is the leading cause of adult mortality in Uganda.

As expected, access to HIV testing centre influenced timing of HIV diagnosis. Distance in kilometres has been used as a measure of physical access to health services which is believed to influence utilisation of health services (6). However, in this study distance to testing centre and timing of HIV diagnosis was significant at bivariate analysis and not at multivariate analysis, instead it was time taken to reach a testing centre that was significant in differentiating early from late testers. This may mean that in this study area characterised with a poor road network and unavailability of transport, time taken to reach a testing centre may be a better proxy measure of physical access to a testing centre other than the distance covered.

Late testing was more frequent among HIV patients who paid for HIV testing. Paying for an HIV test acting as a barrier to early testing was not surprising. In Uganda where clients pay fees for HIV testing, the routinely advertised free days for certain groups attract hundred of clients (15). This is further supported by another study donein Uganda on use of bed nets which reported cost of an item or service as a factor influencing health seeking behaviour and use of treatment and preventive strategies in Uganda (14). This could also be related to the poverty level, given that $38 \%$ of the population in Uganda earn less than one US dollar a day, no much saving would be left to pay for the HIV test even at the current subsidised fee of 1.14 US dollars. On the other hand, it is likely that those with advanced HIV disease or AIDS are more likely to be willing to pay. Another barrier to early testing appears to be lack of knowledge of availability of testing services. This is similar to what has been observed among gay and bisexual men in Europe and USA (16).

Late and early testers had a lot in common regarding the belief of knowing one is HIV sero-status. This could be a result of bias which may have been created during the interview of study subjects since they were interviewed after pre-test counselling. This belief could have been influenced by the information given during pre-test counselling. Inspite of the effect of pre-test counselling, late testing was more likely among clients who had a negative belief towards the importance of knowing one's HIV sero status. The respondents often mentioned quick progress of the disease and dying faster as effect of one knowing his / her sero status which may be an expressed form of fear of positive results. It has been shown that fear of positive HIV results may be a barrier to HIV testing (17-21). Similarly as expected late testing was favoured by having an illness in the last two months suggesting that HIV/AIDS related or similar symptoms may actually influence the decision to undertake a test (16-19).

In view of our findings, to promote early diagnosis of HIV infection, HIV testing should be promoted for every sexually active adult not only young people and those who are already sick (7). There is also need for providing free or subsidised HIV counselling and testing services, intensifying sensitisation campaigns to create awareness on availability of testing services, and to address the negative belief regarding knowing one's HIV sero status. With improved HIV care and availability of $\mathrm{ARVs}$, the population awareness of the benefits of early diagnosis needs to be emphasised.

\section{REFERENCES}

1. Sullivan, A. X., Curtis, H., Sabin, C.A. and Johnson, M.A. Newly diagnosed HIV infections: review in UK and Ireland. Brit. Med. J. 2005; 330: 1301-1302.

2. Castilla, J., Sobrino, P., de la Fuente, L., et al. Late diagnosis of HIV infection in the era of highly active antiretroviral therapy: consequences for AIDS incidence. AIDS. 2002; 16: 1945-1951.

3. Valdiserri, R. O., Holtgrave, D.R. and West, G.R [Editorial Review]. Promoting early HIV diagnosis and entry into care. AIDS. 1999; 13: 2317-2330.

4. Weinhardt, I.S., Carey, M.P., Johnson, B.T. and Bickham, N.L. Effects of HIV counseling and testing on sexual risk behaviour: a meta-analytic review of published research, 1985-1997. Am. J. Public Health. 1999; 89: 1397-1405.

5. Sweat, M., Gregorich, S., Sangiwa, G., et al. Cost effectiveness of voluntary HIV-1 counseling and testing in reducing sexual transmission of HIV-1 in Kenya and Tanzania. Lancet. 2000; 356: 113-121.

6. Uganda Bureau of statistics, ORC Marco. Uganda Demographic and Health Survey Report 2000-2001. Calverton, Maryland, USA: UBOS \& ORC Marco; 2001.

7. Nuwaha, F., Kabatesi, D., Muganwa, M. and Whalen, C.C. Factors influencing acceptability of voluntary counseling and testing for HIV in Bushenyi district of Uganda. East Afr. Med. J. 2002; 79: 626-632.

8. Weidle, P.I., Malamba, S., Mwebaze, R., et al. Assessment of a pilot antiretroviral drug therapy programme in Uganda: patients' response, survival, and drug resistance. Lancet. 2002; 360: 34-40.

9. Couturier, E., Schwoebel, Y., Michon, C., et al. Determinants of delayed diagnosis of HIV infection in France, 1993-1995. AIDS. 1998; 12:795-800.

10. Girardi, E., Aloisi, M., Arici, C., et al. Delayed presentation and late testing for HIV: Demographic and behavioral risk factors in a multicenter study in Italy. J. AIDS. 2004; 36: 951-959. 
11. World Health Organization. WHO case definitions for AIDS surveillance in adults and adolescents. Wkly Epidemiol Record. 1994; 37: 273-275.

12. Girardi, E., Sampaolesi, A., Gentile, M., Nurra, G. and Ippolito, G. Increasing proportion of late diagnosis of HIV infection among patients with AIDS in Italy following introduction of combination antiretroviral therapy. J. AIDS. 2000; 25: 71-76.

13. Centre for Disease Control and Prevention. Late Yersus Early Testing of HIV: 16 Sites, United States, 2000-2003. MMWR Morb Mortal Wkly Rep. 2003; 52: 581-586.

14. Nuwaha, F. Factors influencing the use of bed nets in Mbarara Municipality in Uganda. Am. J. Trop. Med. Hyg. 2001; 65: 877-882.

15. Alwano-Edyegu, M.G. and Marum, E. Knowledge of power: voluntary HIV counseling and testing in Uganda. UNAIDS; Geneva; 1999.

16. Stall, R., Hoff, C., and Coates, T.J. Decision to get HIV tested and to accept antiretroviral therapies among gay/bisexual men: implication of secondary prevention efforts. J. AIDS. 1999; 11: 151-160.
17. Irwin, K., Yaldiserri, R.O. and Holmberg, S.D. The acceptability of voluntary at1tibody testing in the United States: a decade of lessons learned. AIDS. 1996; 10: 1707-1717.

18. Killewo, J.Z., Kwesigabo, G., Comoro, C., et al. Acceptability of voluntary HIV testing with counseling in rural village in Kagera, Tanzania. AIDS Care. 1998; 10: 431-439.

19. Low-Beer, D. and Stoneburner, R.L. Behavior and communication change in reducing HIV: Is Uganda unique? Afr. J. AIDS Res. 2003; 2: 9-21.

20. Asiimwe-Okiror, G., Opio, A.A., Musinguzi, J., et al. Change in sexual behavior and decline in HIV infection among young pregnant women in urban Uganda. AIDS. 1997; 11: 1757-1763.

21. Simon, P.A., Weber, M., Ford, W.L., et al. Reasons for HIV antibody test refusal in a heterosexual sexually transmitted disease clinic population. AIDS. 1996; 10: 1549-1553. 